[(4-Cyanophenyl)difluoromethyl] [4-(4-pentylcyclohexyl)phenyl]ether (5a): Yield $78 \% ;{ }^{1} \mathrm{H}-\mathrm{NMR} \delta: 0.90(\mathrm{t}, 3 \mathrm{H}), 0.95-1.6(\mathrm{~m}, 13 \mathrm{H}), 1.88(\mathrm{mc}, 4 \mathrm{H}), 2.48$ (mc, $1 \mathrm{H}), 7.18(\mathrm{mc}, 4 \mathrm{H}), 7.82(\mathrm{mc}, 4 \mathrm{H})$; MS $m / z: 397\left(\mathrm{w}, \mathrm{M}^{+}\right), 152(100 \%$, $\mathrm{CF}_{2} \mathrm{C}_{6} \mathrm{H}_{4} \mathrm{CN}$ ).

[(4-Fluorophenyl)difluoromethy] [(4-(4-pentylcyclohexyl)phenyl]ether (5b): Yield $65 \% ;{ }^{1} \mathrm{H}-\mathrm{NMR} \delta: 0.90(\mathrm{t}, 3 \mathrm{H}), 0.95-1.55(\mathrm{~m}, 13 \mathrm{H}), 1.88(\mathrm{mc}, 4 \mathrm{H}), 2.47$ (mc, 1H), $7.16(\mathrm{mc}, 2 \mathrm{H}), 7.19(\mathrm{~s}, 4 \mathrm{H}), 7.73(\mathrm{mc}, 2 \mathrm{H})$; MS m/z: $390\left(\mathrm{M}^{\oplus}\right), 145$ $\left(100 \%, \mathrm{CF}_{2} \mathrm{C}_{6} \mathrm{H}_{4} \mathrm{~F}\right)$.

[4-(4-Pentylcyclohexyl)phenyl] [(4-trifluoromethylphenyl)difluoromethyl] ether $(5 \mathrm{c})$ : Yield $68 \% ;{ }^{1} \mathrm{H}-\mathrm{NMR} \delta: 0.91(\mathrm{t}, 3 \mathrm{H}), 0.95-1.55(\mathrm{~m}, 13 \mathrm{H}), 1.89$ (mc, 4H), 2.47 (mc, 1H), $7.18(\mathrm{~s}, 4 \mathrm{H}), 7.80(\mathrm{q}, 4 \mathrm{H}) ; \mathrm{MS} m / z: 440\left(\mathrm{M}^{\oplus}\right), 327$ $\left(\mathrm{C}_{3} \mathrm{H}_{4} \mathrm{C}_{6} \mathrm{H}_{4} \mathrm{OCF}_{2} \mathrm{C}_{6} \mathrm{H}_{4} \mathrm{CF}_{3}\right), 314\left(\mathrm{C}_{2} \mathrm{H}_{3} \mathrm{C}_{6} \mathrm{H}_{4} \mathrm{OCF}_{2} \mathrm{C}_{6} \mathrm{H}_{4} \mathrm{CF}_{3}\right), 195(100 \%$, $\left.\mathrm{CF}_{2} \mathrm{C}_{6} \mathrm{H}_{4} \mathrm{CF}_{3}\right)$.

[4-(4-Pentylcyclohexyl)phenyl] [(4-trifuoromethoxyphenyl)difluoromethyl] ether (5d): Yield 72\%; ${ }^{1} \mathrm{H}-\mathrm{NMR} \delta: 0.90(\mathrm{t}, 3 \mathrm{H}), 0.95-1.5(\mathrm{~m}, 13 \mathrm{H}), 1.89$ (mc, 4H), $2.47(\mathrm{mc}, 1 \mathrm{H}), 7.18(\mathrm{~s}, 4 \mathrm{H}), 7.31(\mathrm{mc}, 2 \mathrm{H}), 7.77(\mathrm{mc}, 2 \mathrm{H}) ; \mathrm{MS} m / z: 456$ $\left(\mathrm{M}^{\oplus}, 211\left(100 \%, \mathrm{CF}_{2} \mathrm{C}_{6} \mathrm{H}_{4} \mathrm{OCF}_{3}\right)\right.$.

[(4-Bromophenyl)difluoromethyl](4-trifluoromethoxy-phenyl)ether (7a): Yield $51 \%$; m.p. $43^{\circ} \mathrm{C}$; MS $m / z: 384 / 382 \quad\left(\mathrm{M}^{\oplus}\right), 207 / 205 \quad(100 \%$, $\left.\mathrm{BrC}_{6} \mathrm{H}_{4} \mathrm{CF}_{2}\right), 126\left(\mathrm{C}_{6} \mathrm{H}_{4} \mathrm{CF}_{2}\right)$

[(4-Bromophenyl)difluoromethyl](3,4-diffuorophenyl)ether (7b): Yield 79 \%; m.p. $39^{\circ} \mathrm{C}$; ${ }^{1} \mathrm{H}-\mathrm{NMR} \delta: 6.95-7.25$ (m, 3H), 7.59 (mc, 4H); MS m/z: 336/334 (w, $\left.\mathrm{M}^{\oplus}\right), 207 / 205\left(100 \%, \mathrm{BrC}_{6} \mathrm{H}_{4} \mathrm{CF}_{2}\right), 126\left(\mathrm{C}_{6} \mathrm{H}_{4} \mathrm{CF}_{2}\right)$

[(4-Bromophenyl)difluoromethyl](3,4,5-trifluorophenyl)ether (7c): Yield $63 \%$; m.p. $46^{\circ} \mathrm{C}$; ${ }^{\prime} \mathrm{H}-\mathrm{NMR} 8: 6.94(\mathrm{mc}, 2 \mathrm{H}), 7.60$ (mc, 4H); MS m/z: 207/ $205\left(100 \%, \mathrm{BrC}_{6} \mathrm{H}_{4} \mathrm{CF}_{2}\right), 126\left(\mathrm{C}_{6} \mathrm{H}_{4} \mathrm{CF}_{2}\right)$

Preparation of compounds 6: A mixture of $20.5 \mathrm{~g}$ (100 mmol) 4-propylcyclohexyl bromide, $1.4 \mathrm{~g}$ (200 mmol) granulated lithium, $11.3 \mathrm{~g}(50 \mathrm{mmol})$ zinc bromide, $80 \mathrm{ml}$ toluene and $20 \mathrm{ml} \mathrm{THF}$ were stirred for $4 \mathrm{~h}$ at r.t. in an ultrasound bath. Then a solution of $0.025 \mathrm{mmol}$ of the compound 7 in $40 \mathrm{ml}$

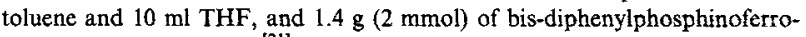
cene palladium dichloride ${ }^{[21]}$ were added; the mixture was stirred for $24 \mathrm{~h}$ at r.t. and then quenched by addition of $100 \mathrm{ml}$ of a saturated aqueous solution of ammonium chloride. The mixture was filtered, the organic phase was separated and evaporated in vacuo. The residue was dissolved in $200 \mathrm{ml}$ hexane; after addition of $2 \mathrm{~g}$ charcoal the mixture was agitated for $30 \mathrm{~min}$. and filtered. The filtrate was concentrated in vacuo and purified by chromatography on silica with hexane as a solvent. The solvent was evaporated in vacuo, and the residue was crystallized twice from ethanol.

\{[4-(4-Propylcyclohexyl)phenyl]difluoromethyl\}(4-trifluoromethoxyphenyl) ether (6a): Yield 46\%; ${ }^{1} \mathrm{H}-\mathrm{NMR} \delta: 0.91(\mathrm{t}, 3 \mathrm{H}), 1.0-1.55(\mathrm{~m}, 9 \mathrm{H}), 1.89(\mathrm{mc}$ $4 \mathrm{H}), 2.52(\mathrm{mc}, 1 \mathrm{H}), 7.15-7.35(\mathrm{~m}, 6 \mathrm{H}), 7.62(\mathrm{mc}, 2 \mathrm{H})$; MS $m / z: 428\left(\mathrm{M}^{\oplus}\right), 251$ $\left(100 \%, \mathrm{C}_{3} \mathrm{H}_{7} \mathrm{C}_{6} \mathrm{H}_{10} \mathrm{C}_{6} \mathrm{H}_{4} \mathrm{CF}_{2}\right), 127\left(\mathrm{C}_{6} \mathrm{H}_{5} \mathrm{CF}_{2}\right)$

(3,4-Difluorophenyl)\{[4-(4-propylcyclohexyl)phenyl]difluoromethyl\}ether (6): Yield $47 \%$; ${ }^{1} \mathrm{H}-\mathrm{NMR} \delta: 0.91(\mathrm{t}, 3 \mathrm{H}), 1.0-1.55(\mathrm{~m}, 9 \mathrm{H}), 1.89(\mathrm{mc}, 4 \mathrm{H})$, 2.53 (mc, $1 \mathrm{H}), 6.95-7.25(\mathrm{~m}, 3 \mathrm{H}), 7.30(\mathrm{mc}, 2 \mathrm{H}), 7.61(\mathrm{mc}, 2 \mathrm{H}) ; \mathrm{MS} m / z: 380$ $\left(\mathrm{M}^{\oplus}\right), 251\left(100 \%, \mathrm{C}_{3} \mathrm{H}_{7} \mathrm{C}_{6} \mathrm{H}_{10} \mathrm{C}_{6} \mathrm{H}_{4} \mathrm{CF}_{2}\right), 127\left(\mathrm{C}_{6} \mathrm{H}_{5} \mathrm{CF}_{2}\right)$.

$\{$ [4-(4-Propylcyclohexyl)phenyl]difluoromethyl\}(3,4,5-trifluorophenyl) ether (6c): Yield $29 \%$; ${ }^{1} \mathrm{H}-\mathrm{NMR}$ 8: $0.91(\mathrm{t}, 3 \mathrm{H}), 1.0-1.6(\mathrm{~m}, 9 \mathrm{H}), 1.89(\mathrm{mc}, 4 \mathrm{H}), 2.53$ (mc, 1H), $6.93(\mathrm{mc}, 2 \mathrm{H}), 7.30(\mathrm{mc}, 2 \mathrm{H}), 7.59(\mathrm{mc}, 2 \mathrm{H}) ; \mathrm{MS} m / z: 398\left(\mathrm{M}^{\oplus}\right), 251$ $\left(100 \%, \mathrm{C}_{3} \mathrm{H}_{7} \mathrm{C}_{6} \mathrm{H}_{10} \mathrm{C}_{6} \mathrm{H}_{4} \mathrm{CF}_{2}\right), 127\left(\mathrm{C}_{6} \mathrm{H}_{5} \mathrm{CF}_{2}\right)$

Received: January 24, 1996 Final version: March 14, 1996

[1] G. Weber, U. Finkenzeller, T, Geelhaar, B. Rieger, L. Pohl, Liq. Cryst. 1989, 5, 1381

[2] S. Matsumoto, H. Hatoh, A. Murayama, Liq. Cryst. 1989, 5, 1345.

[3] H. J. Plach, P. A. Breddets, B. Rieger, Solid State Technol. 1992, 186.

[4] E. Bartmann, D. Dorsch, U. Finkenzeller, H. A. Kurmeier, E. Poetsch, 18th Freiburger Arbeitstagung Flüssigkristalle, Freiburg FRG, 1990, lecture 8 .

[5] E. Bartmann, U. Finkenzeller, H. A. Kurmeier, E. Poetsch, V. Reiffenrath, B. Scheuble, 13th Int. Liquid Crystal Conf., Vancouver B.C., 19\%, lecture SYN 13.

[6] H. J. Plach, G. Weber, B. Rieger, SID 90, Las Vegas 1990, lecture 7.1.

[7] E. Bartmann, D. Dorsch, U. Finkenzeller, Mol. Cryst, Liq. Cryst. 1991, 204,77 .

[8] Y. Goto, T. Ogawa, S. Sawada, S. Sugimori, Mol. Cryst. Liq. Cryst. 1991, 209,1 .

[9] E. Bartmann, 10th Eur. Symp. Fluorine Chem., Padua 1992, lecture A40 (abstract in J. Fluorine Chem. 1992, 58, 167).

[10] H. J. Plach, S. Naemura, B. Rieger, E. Bartmann, E. Poetsch, SID 92 , Boston, 1992 lecture 4.1.

[11] H. J. Plach, V. Reiffenrath, G. Weber, Display Technol. (SPIE) 1992, 1815,256
[12] H. Yamamoto, Y. Kubo, F. Takeshita, K. Terashima, Y. Goto, S. Sawada, Proc. 18th Japan Liquid Crystal Conference, Nïigata, 1992, 100.

[13] E. Bartmann, J. Krause, J. Fluorine Chem. 1993, 61, 117.

[14] E. Bartmann, Ber. Bunsenges. Phys. Chem. 1993, 97, 1349.

[15] E. Bartmann, U. Finkenzeller, E. Poetsch, V. Reiffenrath, K. Tarumi, 22. Freiburger Arbeitstagung Flüssigkristalle, Freiburg FRG, 1993, lecture 8

[16] E. Bartmann, J. Krause, K. Tarumi, 23. Freiburger Arbeitstagung Flüssigkristalle, Freiburg FRG, 1994, lecture 27.

[17] E. Poetsch, E. Bartmann, H. A. Kurmeier, B. Rieger, U. Finkenzeller, Ger. Pat. Appl. 4006921 (1991) [Chem. Abstr. 1992, 116, 31599v].

[18] A. Haas, M. Spitzer, M. Lieb, Chem. Ber. 1988, 121, 1329.

[19] E.-I. Negishi, Acc. Chem. Res. 1982, 15, 340.

[20] T. Hayashi, M. Konishi, Y. Kobori, M. Kumada, T. Higuchi, K. Hirotsu, J. Am. Chem. Soc. 1984, 106, 158.

[21] E. Poetsch, Kontakte, E. Merck, Darmstadt 1988, 15

[22] C. Petrier, J. C. De Souza Barbosa, C. Dupuy, J. L. Luche, J. Org. Chem 1985, 50, 5761.

[23] R. Eidenschink, J. Krause, L. Pohl, Ger. Pat. 2701591 (1978) [Chem. Abstr. 1978, 89, 215085e]

[24] M. Bremer, K. Tarumi, Adv. Mater. 1993, 5, 842.

[25] J. B. Niederl, V. Niederl, S. Shapiro, M. E. McGreal, J. Am. Chem. Soc. 1937, 59, 1113.

[26] A. M. Kuliev, A. B. Kuliev, F. N. Mamedov, Zh. Org. Khim. 1965, 1, 1787 [Chem. Abstr. 1966, 64, 3392e]

[27] S. A. Sarankina, A. B. Kuchkarov, F. K. Kurbanov, B. V. Rakhimova, Izv. Vyssh. Uchebn. Zaved. Khim. Khim. Tekhnol. 1975, 18, 743 [Chem. Abstr, 1975, 83, 78776r].

[28] R. Eidenschink, L. Pohl, M. Roemer, B. Scheuble, Ger. Pat. 32311984 707 [Chem. Abstr. 1984, 101, 63770a]

[29] U. Finkenzeller, Kontakte, E. Merck, Darmstadt 1988, 7.

[30] U. Finkenzeller, T. Geelhaar, G. Weber, L. Pohl, Liq. Cryst. 1989, 5, 313.

\section{Surface Modification and Patterning of Conjugated Polymers with Near-field Optical Microscopy**}

\section{By P. K.Wei, J. H. Hsu, B. R. Hsieh, and W. S. Fann*}

Conjugated polymers can be considered as the model systems for quasi-one-dimensional semiconductors. ${ }^{[1]}$ In addition to the interest in the study of the physics of lowdimensional systems, the device applications of conjugated polymers in areas such as light emitting diodes (LEDs), thin film transistors, and photo-detectors, have attracted much attention in recent years. ${ }^{[2-4]}$

In some conjugated polymers, such as poly( $p$-phenylenevinylene) (PPV), the $\pi$-bonds can be oxidized to form carbonyl groups under exposure to a high optical fluence in oxygen environments. ${ }^{[5,6]}$ During the photo-oxidation, defects are introduced into the polymers. These defects shorten the conjugation length of the $\pi$ electrons and result in a shift of the absorption bands from the visible to the UV

[*] Prof. W. S. Fann, Dr. P. K. Wei, Dr. J. H. Hsu

Institute of Atomic and Molecular Sciences, Academia Sinica, and

Department of Physics, National Taiwan University

P.O. Box 23-166, Taipei, Taiwan (ROC).

B. R. Hsieh

Xerox Corporation

The Wilson Center for Research and Technology

800 Phillips Road, 114-39 D, Webster, NY 14580 (USA)

[**] We would like to acknowledge Dr. Y. Chiu, Dr. M. Hayashi and Professor J. Hsu for the critical reading of the manuscript. This research was funded by the National Science Council, Taiwan (ROC). 
range. The absorption changes are only observed in an air environment and not under vacuum. In addition, a carbonyl stretching vibration appears in the IR spectra of the irradiated samples indicating that the process is photooxidation, and not simple photodegradation (Scheme 1). The photo-oxidation induced defects also quench the luminescence and concomitantly increase the photo-conductivity. ${ }^{[7]}$

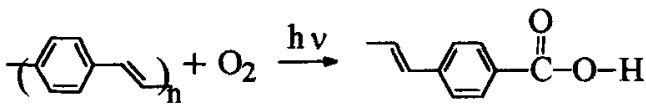

Scheme 1 .

The newly developed technique near-field scanning optical microscopy (NSOM) is an ideal tool for photooxidation studies on the nanometer length scale. ${ }^{[8-11]}$ NSOM combines the high spatial resolution of scanning probe microscopy with the advantages of conventional far field optical microscopy, i.e., a non-destructive nature and versatility of the contrast mechanisms. NSOM is a valuable tool, not only for obtaining optical images beyond the diffraction limit but also to modify materials on the nanometer scale. NSOM has found application in the areas of magnetic recording, lithography and membrane biology. ${ }^{[12-15]}$ We envision that NSOM can be a powerful tool for characterizing the oxidized surface defects in thin film devices such as LEDs and FETs.

Understanding the near-field distribution of the point light source used in NSOM is important for the interpretation of the near field images. Betzig et al. have used single molecule detection to probe the near-field distribution. ${ }^{[16]}$ The photo-chemical reaction approach presented in this paper provides a new method to measure the two-dimensional intensity distribution. Photo-oxidation was initiated on the polymer surface by applying high near-field intensity. The absorption changes due to the photo-oxidation can be directly related to the near-field distribution. NSOM can then "read" these changes via the absorption image subsequently.

Experiments were performed on DP-PTV, poly(3,4diphenyl-2,5-thienylene vinylene). DP-PTV thin films were prepared via the chlorine precursor route (CPR) as shown in Scheme 2. Polymerization of 2,5-bis(chloromethyl)-3,4-

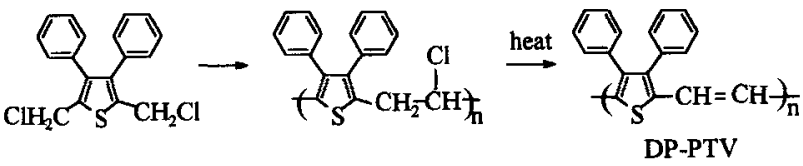

Scheme 2.

diphenylthiophene with an equivalent of potassium $t$ butoxide gave the chlorine precursor polymer of DP-PTV. Thin films of the precursor polymer were deposited by spin casting on a glass substrate using a $2 \%$ THF solution and the precursor was then converted to DP-PTV at $150^{\circ} \mathrm{C} / 1 \mathrm{~h}$ to give DP-PTV thin films. The sample has a thickness of $7000 \AA$ and an absorption peak around $540 \mathrm{~nm}$.

The optical fluence is critical for photo-oxidation chemistry. It is important to measure how much power is necessary to initiate such a process on the DP-PTV. Figure 1 shows the absorption changes of DP-PTV when it was exposed to $514.5 \mathrm{~nm}$ argon laser light in the far field condition. The solid

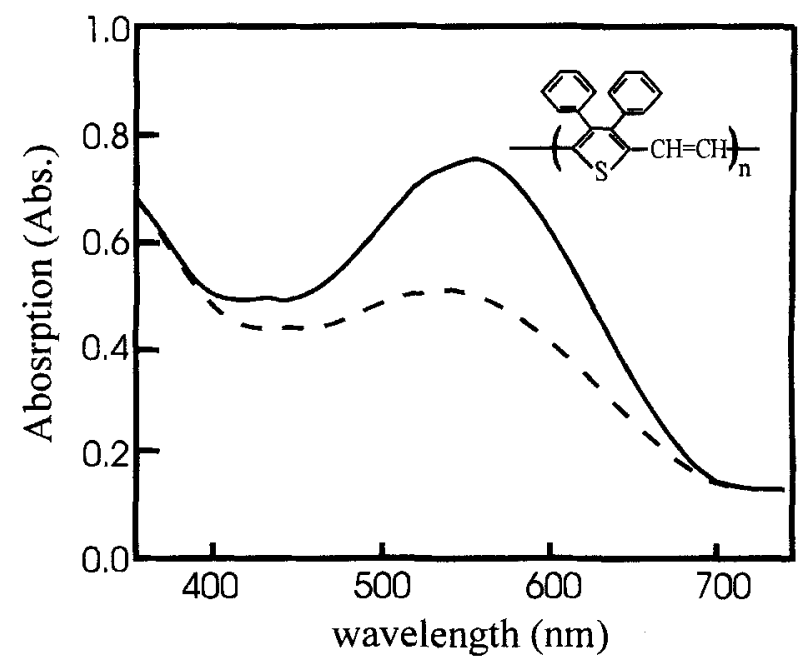

Fig. 1. The absorption spectra of the DP-PTV sample in its original state (solid line) and after exposure to $3 \mathrm{~kJ} / \mathrm{cm}^{2}$ of $514.5 \mathrm{~nm}$ Argon laser fluence (dashed line).

line in Figure 1 shows the absorption spectrum of the sample in its original state, and the dashed line is the absorption spectrum after exposure to $3 \mathrm{~kJ} / \mathrm{cm}^{2}$ of optical fluence. The optical data shows that the absorption at $540 \mathrm{~nm}$ is approximately reduced to $3 / 4$ of the original state. Because the $\pi-\pi^{*}$ band is fairly broad, the absorption difference between the $514.5 \mathrm{~nm}$ and $543.5 \mathrm{~nm}$ is quite small. Hence the far field data can be used to estimate the fluence needed for the near-field experiments which used $543.5 \mathrm{~nm}$ light.

Figure 2 shows a schematic diagram of the transmission mode NSOM used for the experiments. Our home-made NSOM was built around a commercial AFM scanning stage (PSI, BD-2). In the heart of the NSOM is a metal-coated tapered fiber probe ${ }^{[17]}$ and the shear force feedback. ${ }^{[18]} \mathrm{A}$ $0.5 \mathrm{~mW}$ green light $\mathrm{He}-\mathrm{Ne}$ laser ( $543.5 \mathrm{~nm}$ wavelength) is coupled into the tapered fiber probe to serve as a near-field source. In shear force feedback, the fiber probe is set into vibration near its resonance. Due to the force between probe and sample surface, the vibrational amplitude reduces when the probe approaches the sample surface. This damping of the vibrational amplitude is used to construct the feedback loop that regulates the probe-sample separation. In the present experiment, the resonant frequency of the probe was around $50 \mathrm{kHz}$. A $10 \mathrm{~mW}$ red light $\mathrm{He}-\mathrm{Ne}$ laser $(632.8 \mathrm{~nm}$ wavelength) is focused at the side wall of the tip end to generate the shear-force signals. The un-damped vibrational amplitude was estimated to be $\sim 50 \AA$ by a modified beam 


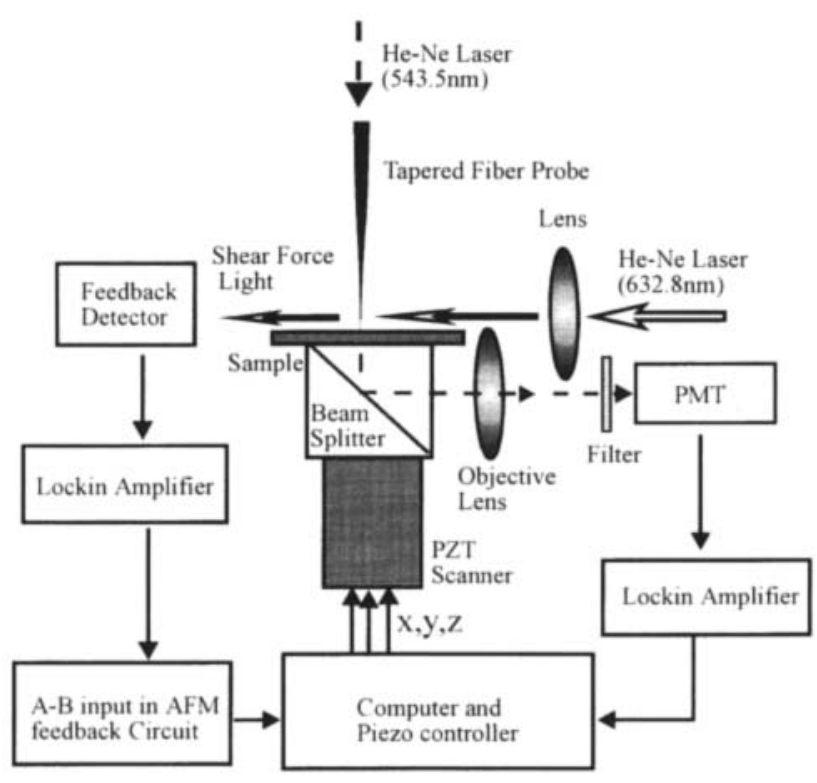

Fig. 2. Schematic diagram of the transmission mode NSOM. The input light is a $0.5 \mathrm{~mW}$ green light $\mathrm{He}-\mathrm{Ne}$ laser ( $543.5 \mathrm{~nm}$ wavelength). The shear force light is a $10 \mathrm{~mW}$ red light $\mathrm{He}-\mathrm{Ne}$ laser $(632.8 \mathrm{~nm}$ wavelength).

diffraction method. ${ }^{[19]}$ The shear force feedback keeps the NSOM operating in a non-contact mode ensuring that the modification observed in the polymers is due to the photooxidation, not physical contact between the probe and the sample surface.

In addition, shear-force signals generate a topographic image similar to the non-contact atomic force microscope. The shear force image is valuable in separating the optical property changes induced by the photo-chemical reactions from the topographic variations. In recording the transmission mode image, a beam splitter with $8 \mathrm{~mm}$ height and $45^{\circ}$ reflecting angle was placed directly below the sample and mounted on the PZT scanning stage. The transmission light reflected by the beam splitter is collected by a long working distance objective (20x, Mitutoyo ultra-long working distance's objective) and sent to a photo-multiplier tube (PMT). A narrow-band pass filter is placed in front of the PMT to eliminate the influence of the shear force light. The signal from the PMT is fed to a lock-in amplifier.

The initiation of photo-oxidation and the recording of the absorption image were carried out as follows. First, the fiber probe provided an intensity of about $2 \mathrm{nW}$ and was maintained at a separation of $\sim 100 \AA$ from the sample surface. After exposure for 3 minutes, the optical absorption is reduced to $90 \%$ of the original level, which is consistent with the previous estimation. Subsequently, the image around this area was read with the transmission mode NSOM. In order not to perturb the properties of the writing area, the reading power was reduced to one-tenth of the writing power. Figure 3 shows the topographic and transmission mode NSOM images, respectively. The white spot in Figure $3 b$ is an oxidized region, which, in turn, enhances the transmission image. The corresponding topographic image in Figure 3a shows no surface variation,

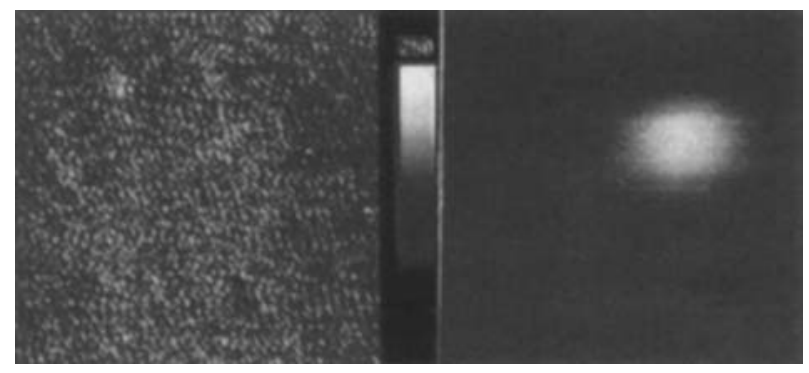

$-1000 \AA$

(a)

(b)
Fig. 3. a) The topographic and b) the corresponding transmission mode NSOM image. The bright region indicates where the sample surface is photooxidized. The dimension of the scan area is $0.93 \mu \mathrm{m} \times 0.93 \mu \mathrm{m}$. The maximum vertical scale in $3 a$ is $250 \AA$.

indicating that the absorption changes are induced by photo-chemical processes. Unlike the modification performed with an atomic force microscope, no heating or physical contact between the tip/sample is involved here. ${ }^{[20]}$ Hence the sample surface remains intact. However the processes are irreversible.

Figure 4 is the contour and cross-section views of the photo-oxidation spot in Figure $3 \mathrm{~b}$. The spot is close to an
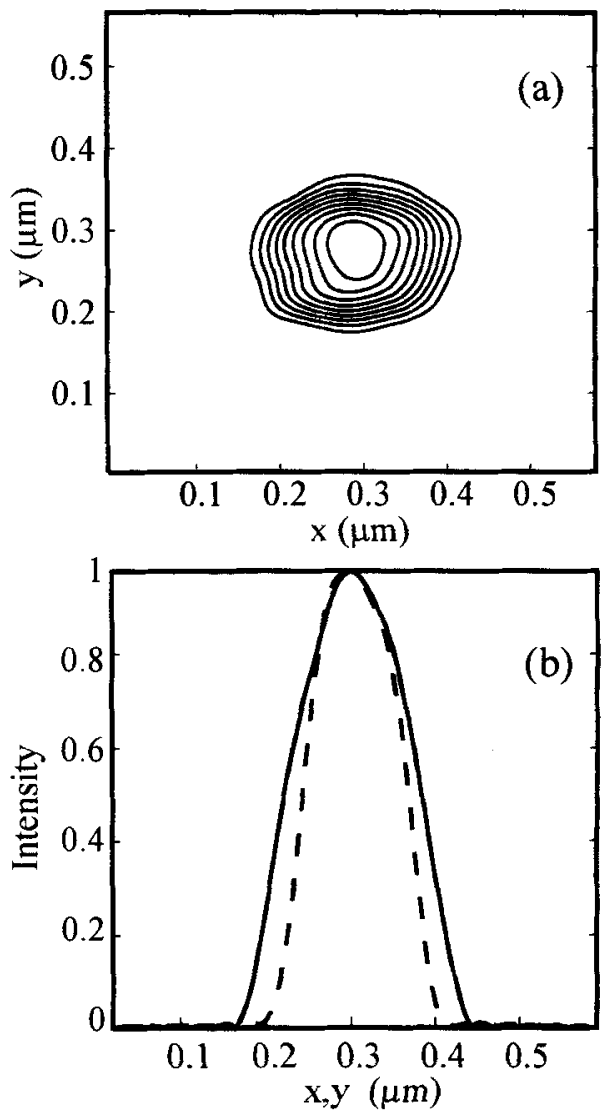

Fig. 4. a) The contour plot of the photo-oxidation region in Fig. 3b. b) The cross-section views of the contour plot in the $x$-axis (solid line) and $y$-axis (dashed line). 
asymmetrical Gaussian distribution with $0.2 \mu \mathrm{m}$ size on the $\mathrm{x}$-axis and $0.14 \mu \mathrm{m}$ on the $\mathrm{y}$-axis. The spot size is the $1 / e$ diameter of the Gaussian distribution. The polarization of the incident light is along the $x$-axis. The studies of the dependence of the asymmetrical distribution on the incident light polarization, as expected from Bethe and Bouwkamp's theory, ${ }^{[21]}$ is currently in progress. Because the same nearfield distribution is used both for writing as well as reading, Figure $4 \mathrm{~b}$ is the auto-correlation of the near-field distribution. The true size of the near-field distribution is 0.14 and $0.1 \mu \mathrm{m}$ on the $\mathrm{x}$ and $\mathrm{y}$-axes, respectively.

Following a similar procedure to that described in the last paragraph, various patterns were written on the polymer surface. Figure 5 a shows line gratings and Figure 5 b shows a letter 'A', both written on DP-PTV. The lithography was performed by manually scanning the sample PZT stage.

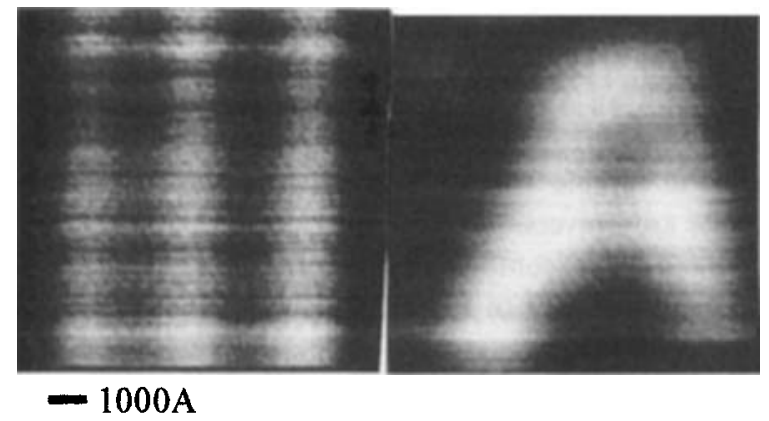

(a)

(b)

Fig. 5. Transmission mode NSOM images of a) Gratings with a $0.14 \mu \mathrm{m}$ gap and $b$ ) a letter ' $A$ ' written by NSOM on the DP-PTV surface.

The measured full width at the half maximum of the line is $0.14 \mu \mathrm{m}$, corresponding to the actual line-width of around $0.1 \mu \mathrm{m}$. Note that the corrugation perpendicular to the lines of grating is due to the noise from the NSOM system.

In summary, an NSOM was used to write/read images on a conjugated polymer film with a resolution of $\sim 0.1 \mu \mathrm{m}$, clearly breaking the diffraction limit. The mechanism of producing the contrast in the optical image is associated with the photo-oxidation processes. High optical intensity from the tapered tip was used to initiate photo-chemistry and subsequently a smaller power was applied to scan the image. This experiment demonstrates the potential of using NSOM to control nanometer scale photo-chemistry on conjugated polymers and to characterize surface defects in polymer thin film devices.

Received: January 31, 1996 Final version: March 19, 1996

[1] A. J. Heeger, S. Kivelson, J. R. Schrieffer, W.P. Su, Rev. Mod. Phys. 1988, $60,781$.

[2] L. M. Burroughs, D. D. C. Bradiey, A. R. Brown, R. M. Marks, K. Mackey, R. H. Friend, P. L. Burns, A. B. Holmes, Nature 1990, 347, 539. D. Braun, A. J. Heeger, Appl. Phys. Lett. 1991, 58, 1982.
[3] F. Garnier, G. Horowitz, X. Peng, D. Fichou, Adv. Mater. 1990, 2, 592.

[4] G. Yu, C. Zhang, A. J. Heeger, Appl. Phys. Lett. 1994, 64, 1540.

[5] M. Yan, L. J. Rothberg, F. Papadimitrakopoulos, M. E. Galvin, T. M Miller, Phys. Rev. Lett. 1994, 73, 744.

[6] T. Zyung, J.-J. Kim, Appl. Phys. Lett. 1995, 67, 3420.

[7] H. Antoniadis, L. J. Rothberg, F. Papadimitrakopoulos, M. Yan, M. E. Galvin, M. A. Abkowitz, Phys. Rev. B 1994, 50, 14911

[8] E. Betzig, J. K. Trautman, Science 1992, 257, 189

[9] U. T. Durig, D. W. Pohl, F. Rohner, J. Appl. Phys. 1986, 59, 3318

[10] A. Lewis, K. Lieberman, Nature 1991, 354, 214.

[11] W. S. Fann, Rev. Sci. Instrum. 1995, 66, 271.

[12] E. Betzig, J. K. Trautman, R. Wolfe, E. M. Gyorgy, P. L. Finn, M. H Kryder, C.-H. Chang, Appl. Phys. Lett. 1992, 61, 142.

[13] J. Hwang, L. K. Tamm, C. Bohm, T. S. Ramalingam, E. Betzig, M. Edidin, Science 1995, 270, 610.

[14] M. Fujihira, H. Monobe, Optronics (Osaka) 1994, 156, 130.

[15] S. Wegscheider, A. Kirsch, H. Bielefeldt, J. C. Meiners, G. Krausch, J. Mlynek, Proc. Near-field Optics 3, European Optical Society Topical Meetings vol. 8, 1995, 189.

[16] E. Betzig, R. J. Chichester, Science 1993, 262, 1422.

[17] E. Betzig, J. K. Trautman, T. D. Harris, J. S. Weiner, R. L. Kostelak, Science 1991, 25I, 1468

[18] E. Betzig, P. L. Finn, J. S. Weiner, Appl. Phys. Lett. 1992, 60, 2484. R. Toledo-Crow, P. C. Yang, Y. Chen, M. Vaez-Iravani, Appl. Phys. Lett. 1992, 60, 2957.

[19] C. C. Wei, P. K. Wei, W. S. Fann. Appl. Phys. Lett. 1995, 67, 3835.

[20] H. J. Mamin, D. Rugar, Appl. Phys. Lett. 1992, 61, 1003.

[21] H. A. Bethe, Phys. Rev. 1944, 66, 163. C. J. Bouwkamp, Philips Res. Rep. 1950, 5,321 , p. 401

\section{A Luminescent Iridium(II) Cyclometallated Complex Immobilized in a Polymeric Matrix as a Solid-State Oxygen Sensor**}

\author{
By Gaetano Di Marco,* Maurizio Lanza, Marco Pieruccini, \\ and Sebastiano Campagna
}

Photoluminescent materials, in which the luminescence output can be modified by interaction with a substrate, are extensively investigated for use as molecular reporters. ${ }^{[1]}$ Luminescence itself is indeed one of the most sensitive analytical techniques; it is non-destructive and relatively cheap and easy to use, and represents a sustainable technology.

Determination of molecular oxygen concentration has important ramifications for medicinal, industrial, and environmental chemistry. ${ }^{[2]}$ As a consequence, several classes of luminescence-based oxygen sensors have been developed in the last few years. ${ }^{[3-6]}$ Most of these make use of transition metal complexes, immobilized in polymeric matrices, as the active luminescent species. The matrices are

[*] Dr. G. Di Marco, Dr. M. Lanza, Dr. M. Pieruccini Istituto di Tecniche Spettroscopiche (ITS) del CNR c. da Papardo-Salita Sperone 31, Vill. S.Agata, I-98166 Messina (Italy) Dr. S. Campagna

Dipartimento di Chimica Inorganica

Analitica e Struttura Molecolare

Università di Messina

c. da Papardo-Salita Sperone 31, Vill. S.Agata, I-98166 Messina (Italy)

[**] The Ministero della Università e della Ricerca Scientifica e Tecnologica and the Consiglio Nazionale delle Ricerche are acknowledged for financial support. 